\title{
Violências, Direitos Humanos e Segurança Pública em Debate
}

Debate On Violence, Human Rights And Public Security

Violencias, Derechos Humanos Y Seguridad Pública En Discusión
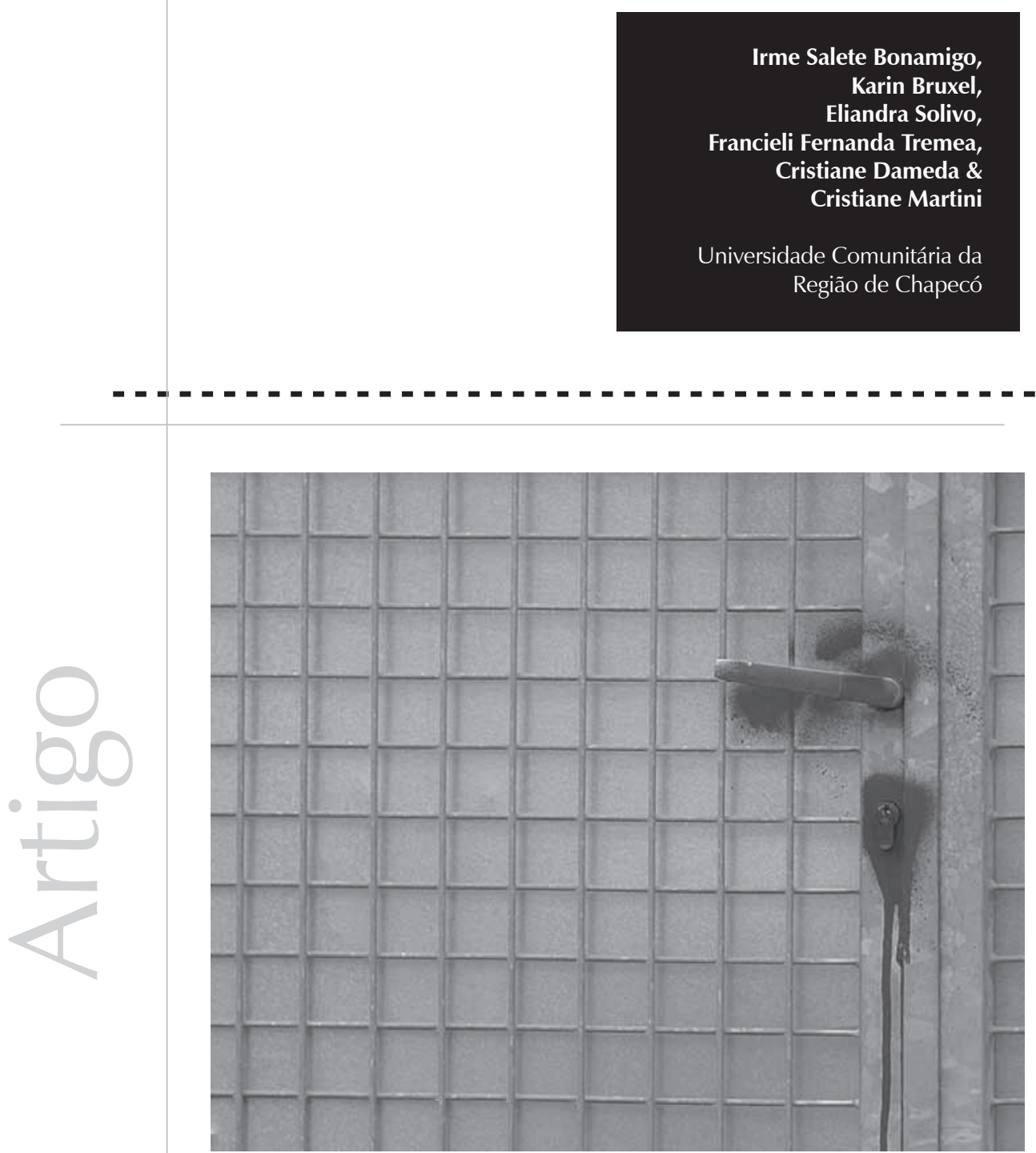
Resumo: Este artigo fundamenta-se em pesquisa que visou a conhecer os índices oficiais sobre práticas violentas do Município de Chapecó (SC), e envolveu procedimentos de métodos mistos por meio de levantamento em bancos de dados sobre mortalidade por causas externas, agressões, furtos e roubos, no período de 1998 a 2008. Os resultados apontaram tanto os acidentes de transporte e os homicídios como os tipos de mortalidade por causas externas que mais afetam o Município, seguidos do suicídio. As principais vítimas são do sexo masculino. Nos registros policiais, destacaram-se acidentes de trânsito, furtos, lesões corporais e roubos. Analisa-se a necessidade de se compreender as violências contemporâneas como um tema transversal do conjunto de políticas públicas, a segurança pública como um direito fundamental, e os Municípios como cogestores da área de segurança e na prevenção de violências. Ressalta-se a importância da constituição de estratégias de prevenção de violências e da elaboração de políticas públicas que levem em consideração as especificidades, as dificuldades e o potencial dos Municípios e da atuação inter ou transdisciplinar, sendo importante a contribuição dos profissionais da Psicologia para esse processo.

Palavras-chave: Violência. Segurança. Políticas públicas. Psicologia.

\begin{abstract}
This article is based on a research that aimed to acknowledge the official index about violent practices concerning the city of Chapecó (SC, Brazil). It included procedures of mixed methods through data raising in data banks about mortality caused by external causes, aggressions and steals from 1998 to 2008. The results revealed that the accidents of transportation and homicides were the types of mortality by external causes that most affect the city, followed by suicide. The main victims are male. In the police reports there were traffic accidents, stealings and body injuries. It is analyzed the need to understand the contemporary violences as a transversal theme in the set of public policies, the public security as an essential right, and the cities as co-managers of the security area and in violence prevention. It is highlighted the importance of the constitution of violence prevention strategies and the development of public policies that consider the specific features, difficulties and potentials of the cities, the inter or trans-subject actuation and the importance of the contribution of Psychology professionals to this process.
\end{abstract}

Keywords: Violence. Security. Public policies. Psychology.

Resumen: Este artículo se fundamenta en investigación llevada a cabo que ha tenido como objetivo conocer los índices oficiales acerca de prácticas violentas referentes al municipio de Chapecó (SC). Han sido involucrados procedimientos de métodos mixtos por medio de levantamiento en bancos de datos sobre mortalidad por causas externas, agresiones, hurtos y robos, en el periodo de 1998 a 2008. Los resultados han señalado los accidentes de transporte y los homicidios como los tipos de mortalidad por causas externas que más afectan el municipio, seguidos del suicidio. Las principales víctimas son del sexo masculino. En los registros policiacos se han destacado los accidentes de tránsito, hurtos, lesiones corporales y robos. Se analiza la necesidad de comprenderse las violencias contemporáneas como un tema transversal del conjunto de políticas públicas, la seguridad pública como un derecho fundamental y los municipios como co-gestores del área de seguridad y en la prevención de violencias. Se remarca la importancia de la constitución de estrategias de prevención de violencias y elaboración de políticas públicas que llevan en consideración las especificidades, dificultades y potenciales de los municipios y de la actuación inter o transdisciplinaria, siendo importante la contribución de los profesionales de la Psicología a ese proceso.

Palabras-clave: Violencia. Seguridad. Políticas públicas. Psicología.

A expressão violência, hoje, comporta diferentes significados; diz respeito a uma multiplicidade de eventos, com motivações diferentes, contextualizados em uma diversidade de espaços. Consideram-se violentas as situações de interação nas quais:

um ou vários atores agem de maneira direta ou indireta, maciça ou esparsa, causando danos a uma ou a mais pessoas em graus variáveis, seja em sua integridade física, seja em sua integridade moral, em suas posses, ou em suas participações simbólicas e culturais (Michaud, 1989, pp. 10-11)
Devido às múltiplas possibilidades de definição do termo, utiliza-se a expressão violências, no plural.

A partir dos anos 90, os Municípios passam a ter um envolvimento maior na esfera da segurança, tendo em vista que as violências se tornam presentes entre as principais preocupações dos brasileiros; ao lado do desemprego e da saúde, cresce a sensação de insegurança, e a população reivindica mais segurança dos governos independentemente de sua esfera (Kahn \& Zanetic, 2009). 
Tendo em vista esse cenário e considerando que historicamente são os estudos realizados nos grandes centros urbanos que têm sido valorizados e considerados nas definições de políticas públicas, percebe-se a necessidade de realização de estudos em Municípios de pequeno e médio porte que coloquem em evidência singularidades que contribuam para a elaboração de estratégias locais a fim de enfrentar as violências.

Nesse sentido, o presente artigo propõe-se a contribuir com o estudo das violências na contemporaneidade, por meio da apresentação e da discussão de pesquisa sobre algumas práticas violentas (mortalidade por causas externas, agressões, furtos e roubos), a qual foi realizada em Chapecó, Município de médio porte, com aproximadamente 180 mil habitantes, localizado na região oeste de Santa Catarina.

\section{Violências em Chapecó como cenário da pesquisa}

Compreende-

se que essas manifestações se devem ao aumento da insegurança, fruto da espetacularização de violências pela mídia

(Michaud, 1989).
Em Chapecó, a preocupação com as violências pode ser identificada pelos comentários cotidianos de seus moradores, pela veiculação de notícias nos jornais locais impressos e televisivos e pela mobilização de pessoas, grupos e governos na discussão e na proposição de ações para o seu enfrentamento. Compreende-se que essas manifestações se devem ao aumento da insegurança, fruto da espetacularização de violências pela mídia (Michaud, 1989), e também ao aumento real de acidentes de transporte, homicídios, suicídios, furtos, agressões e roubos, conforme os indicadores que serão apresentados e discutidos posteriormente.

Segundo Bonamigo (2007), podem ser identificados, em Chapecó, desde o final da década de 90, movimentos ante as violências pela sociedade civil. O Fórum Municipal pelo Fim da Violência e Exploração Sexual
Infanto-Juvenil, criado em 1998, mantém-se, ainda hoje, por meio de vinculações com o fórum estadual e nacional e outros fóruns da infância e adolescência, colocando em pauta questões relacionadas às violências que atingem crianças e adolescentes. O Fórum Chapecoense de Estudos e Combate à Violência (FECOV) teve o seu auge em 2000 e 2001, quando buscou mobilizar pessoas e instituições e potencializar ações das instituições de combate à violência por meio de eventos e reivindicações ao poder público; entretanto, desfez-se em 2003 por dificuldades de articulação entre seus participantes. O Fórum Permanente pela Paz teve sua atuação vinculada à Campanha da Fraternidade Ecumênica de 2005.

Há, ainda, dois grupos de pesquisa vinculados à Universidade Comunitária da Região de Chapecó (Unochapecó) que contribuem com a produção de conhecimento sobre o tema. O Núcleo de Estudos sobre Violência (NESVI), constituído em 1999, desenvolve projetos de pesquisa e extensão sobre diversos tipos de violências, detectando situações de risco e violação dos direitos fundamentais, de modo a contribuir com a construção da cidadania. O Grupo de Estudos e Pesquisa de Gênero Fogueira, criado em 2000, análisa a manifestação de preconceitos ligados aos aspectos das relações sexo-gênero nos diferentes contextos da ação acadêmica e busca interferir criticamente nas relações sociais.

Por parte do Estado, nesse período, houve a configuração de novos dispositivos de controle e de gestão das violências: o policiamento comunitário, o Programa Tolerância Zero e o Programa Segurança Máxima. A polícia comunitária foi constituída a partir de 2001, pelo Estado de Santa Catarina, com a Federação e com o governo municipal. Sustentada na filosofia da participação popular e da prevenção, o dispositivo acontece por meio da criação e do funcionamento de 
Conselhos Comunitários de Segurança (Consegs), compostos por membros da polícia civil, da polícia militar e de representantes das comunidades. Atualmente, há cinco Consegs em diferentes regiões da cidade, que tiveram início com forte participação comunitária; no entanto, essa participação diminuiu gradativamente. De um modo geral, as práticas predominantes em sua atuação são de policiamento ostensivo tradicional.

O Programa Tolerância Zero, lançado no final de 2006, teve a sua ação focada na repressão e na punição dos delitos, por meio de operações policiais e do uso de tecnologias de vigilância e de controle da criminalidade. O programa envolveu diversos órgãos em sua composição, mas as ações se restringiram à polícia militar, à polícia civil, à mídia local e à Prefeitura Municipal. Em 2011, foi substituído pelo Programa Segurança Máxima, desenvolvido em parceria pelo Estado e Município, com o objetivo de aumentar a estrutura, o número de equipamentos e de policiais da polícia militar e da polícia civil.

Apesar de não se ter resultados sistematizados sobre a atuação dos coletivos descritos, podese perceber o quanto a sua presença alimenta o debate sobre violências, direitos humanos e segurança pública, o qual possibilita desnaturalizar situações de violência e reivindicar e avaliar políticas sociais. Nesse cenário, compreende-se que os indicadores sobre mortalidade por causas externas, agressões, furtos e roubos produzidos por esta pesquisa podem contribuir para qualificar a ação desses coletivos, pois permitem a identificação de ocorrências que se destacam em Chapecó.

\section{Método}

Realizou-se a análise epidemiológica descritiva dos dados de mortalidade por causas externas para o Município de Chapecó disponíveis no Sistema de Informação sobre
Mortalidade (SIM), do Ministério da Saúde, no período de 1998 a 2008, segundo os subgrupos específicos (acidentes, suicídios e homicídios), os sexos e as faixas etárias, utilizando proporções e taxas por 100.000 habitantes. As taxas de homicídio e suicídio também foram analisadas de acordo com o meio utilizado. Foram comparadas também as taxas de homicídios entre os diferentes Municípios do Estado de Santa Catarina. Os dados foram coletados na home page do DATASUS (MS) (http://www.datasus.gov.br), da Secretaria do Estado da Saúde de Santa Catarina (http://www.saude.sc.gov.br).

Foi feito também um levantamento nos boletins de ocorrência registrados nos bancos de dados da polícia civil, do $2^{\circ}$ Batalhão da Polícia Militar de Chapecó e do 6으 Batalhão de Bombeiro Militar em sua frequência e periodicidade, utilizando taxas por 100.000 habitantes, no período de 1998 a 2008.

Neste estudo, foram utilizadas as classificações da CID-10 ${ }^{\text {a }}$ (2008) revisão para os grupos de causas de mortes, mais especificamente, os códigos da CID-BR-10 (2008) e os códigos do SIM para identificação dos Municípios incluídos no estudo. A população usada no cálculo das taxas foi extraída das projeções e dos censos demográficos do IBGE.

\section{Resultados}

Compreende-se que, em um estudo sobre violências, torna-se importante considerar as estatísticas oficiais não como fatos indiscutíveis, mas como informação integrada ao contexto em que foram produzidas, sendo atravessadas em sua produção por situações heterogêneas, condições insatisfatórias e pelos sentidos diversos atribuídos pelos profissionais em seu registro. É importante levar em conta a complexidade, a ambivalência e a contaminação presentes nas fontes oficiais. Mesmo assim, se forem avaliados seus limites e potenciais, podem ser consideradas como 
indicadores que possibilitam identificar tendências, e podem ser complementadas através de outras pesquisas quantitativas e qualitativas.

A denominação causas externas é utilizada pela Organização Mundial de Saúde para se referir à mortalidade provocada por um conjunto de eventos que engloba todas as formas de acidentes, suicídios, homicídios, as mortes ocorridas nas guerras e aquelas advindas do confronto com a polícia. Como a distribuição dessas mortes não é homogênea entre regiões do Brasil, busca-se conhecer as taxas referentes ao Município de Chapecó e estabelecer algumas comparações com outros Municípios, com o Estado de Santa Catarina e com a média nacional. A Tabela 1 discrimina as taxas referentes às causas externas de Chapecó, Santa Catarina e Brasil, entre 1998 e 2008, possibilitando-nos visualizar os altos índices de óbitos.

Tabela 1. Taxa de mortalidade por causas externas em Chapecó, SC e Brasil

\begin{tabular}{llllllllllll}
\hline Local & 1998 & 1999 & 2000 & 2001 & 2002 & 2003 & 2004 & 2005 & 2006 & 2007 & 2008 \\
\hline Chapecó & 77,13 & 79,1 & 86,4 & 73,4 & 80,9 & 86,8 & 81,2 & 89,2 & 74,5 & 87,5 & 109 \\
Santa Catarina & 63,4 & 64,1 & 61,8 & 62,3 & 66,7 & 67,1 & 67,4 & 67,3 & 64,6 & $\mathrm{x}$ & $\mathrm{x}$ \\
Brasil & 72,7 & 71,3 & 69,7 & 70,2 & 72,5 & 71,6 & 70,2 & 69,3 & 68,7 & $\mathrm{x}$ & $\mathrm{x}$ \\
\hline
\end{tabular}

Nota: Taxa por 100 mil habitantes. Fonte: SIM - Ministério da Saúde

Dentre os subgrupos das causas externas, os acidentes de transporte estão no topo das causas que mais matam. Considera-se acidente de transporte, conforme definição do CID-10, o acidente que envolve veículo utilizado para o transporte de pessoas ou mercadorias de um lugar para outro. No período entre 1998 a 2008, observa-se um crescimento significativo das taxas, principalmente nos anos 2005, 2007 e 2008, variando entre o coeficiente menor, de 25,96 óbitos, por acidentes de transporte por 100 mil habitantes em 2003, para o maior, de 51,81, no ano 2008. Ao se analisar as médias de Santa Catarina, no período de 1998 a 2006 (não havia dados disponibilizados para os anos 2007 e 2008) as taxas não apresentaram muita variação; a menor ocorreu em 2000, com 28,1 óbitos, e a maior, no ano 2005, com 33,2. Em termos de país, as médias nacionais variam entre 17,5 e 19,9, sendo menores que as de Chapecó e as de Santa Catarina. As principais vítimas dos acidentes de transporte se localizam na faixa etária entre 20 e 49 anos e são do sexo masculino. Em 2008, por exemplo, 39,00 são óbitos do sexo masculino, e 12,81, do sexo feminino.

Em segundo lugar, destacam-se as taxas de óbitos por homicídios. No período investigado, nota-se um aumento gradativo nos índices de Chapecó, com decréscimo apenas nos anos 2000, 2004 e 2005, considerando-se que, no ano 2005, ocorre a menor taxa de óbitos $(10,63)$, contrastando com a taxa de 27,36 óbitos por homicídios no ano 2008. As médias de Santa Catarina são menores que as de Chapecó e variam pouco no período, oscilando entre a taxa de 7,6 (1999) e 11,9 (2003). Já o País apresenta altas taxas, quando comparadas às do Estado, e mais próximas do coeficiente de óbitos ocorridos em 2008 em Chapecó, variando entre 25,9 em 1998, e 26,6 em 2005. As principais vítimas dos homicídios também têm entre 20 e 49 anos, e são do sexo masculino. A maioria dos homicídios é perpetrada com uso de arma de fogo; em segunda posição, situam-se as agressões por objeto cortante ou penetrante, e, em terceiro lugar, as agressões por meio ignorado. 
Os coeficientes padronizados de mortalidade por homicídios (taxa por 100 mil habitantes) permitiram estabelecer uma comparação entre os diferentes Municípios do Estado de Santa Catarina no período estudado, conforme pode ser observado na Tabela 2.

Tabela 2. Ranking das taxas (por 100 mil habitantes) de homicídio para SC; Municípios com mais de 100 mil habitantes

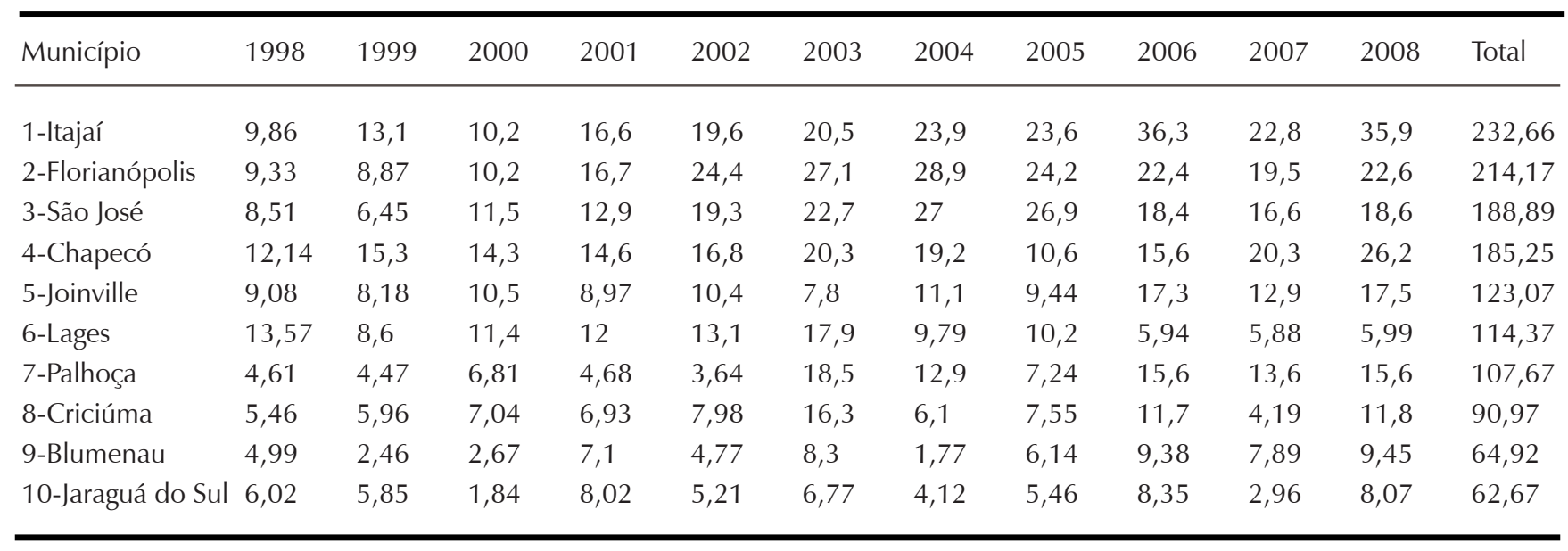

Fonte: SIM - Ministério da Saúde

No quadro geral dos Municípios do Estado, Chapecó localizou-se na 6a posição. Quando comparado com os outros Municípios do Estado, com mais de 100 mil habitantes (total de 10 municípios), situou-se como o quarto Município com mais elevado coeficiente de homicídio. Chapecó foi comparado, também, com outros Municípios da região oeste, com mais de 20 mil habitantes (total de 12 Municípios), dentre os quais se classificou como o segundo Município com maior coeficiente de homicídios.

Foi comparado, ainda, na região da AMOSC (Associação dos Municípios da Região Oeste de Santa Catarina), com Municípios com mais de 9 mil habitantes (total de 5), e Chapecó classificou-se como o primeiro Município com maior coeficiente de homicídios.

Em terceiro lugar, classificam-se os índices de óbitos por suicídios, não havendo um crescimento ao longo do período investigado, mas apenas variações, destacando-se as taxas dos anos 2000 (12,93), $2003(12,03)$ e 2005 (12,41); as menores taxas de suicídio por 100 mil habitantes ocorreram em $2006(6,93)$ e 2007 (6,21). Em Santa Catarina, as taxas foram menores que as de Chapecó, variando entre os coeficientes 6,4 (2006) e 7,9 (1998). As altas taxas de suicídio em Chapecó e Santa Catarina se destacam quando comparadas com as médias do País, cuja variação foi entre 4 (1999 e 2000) e 4,6 (2005 e 2006). As vítimas de suicídio, em sua maioria, são do sexo masculino e também se situam na faixa etária de 20 a 49 anos. O meio utilizado para a prática do suicídio, tanto pelo sexo masculino como pelo feminino, em primeiro lugar, é enforcamento, estrangulamento e sufocação, em segundo lugar, arma de fogo, e, em terceiro lugar, intoxicação por pesticidas.

A análise dos delitos registrados pela polícia civil, de acordo com a Tabela 3, evidencia que o furto é a ocorrência mais registrada no Município, seguida de dano (destruir, inutilizar ou deteriorar coisa alheia), acidente de trânsito com dano, acidente de trânsito com lesão corporal de homem, 
lesão corporal dolosa contra homem, lesão corporal dolosa contra mulher, roubo, estelionato, vias de fato (molestar fisicamente alguém, sem que haja lesão física como resultado da ação) e acidente de trânsito com lesão corporal contra mulher.

Tabela 3. Taxa (por 100 mil habitantes) dos principais registros da polícia civil - Chapecó/SC

\begin{tabular}{|c|c|c|c|c|c|c|c|c|c|c|}
\hline Delitos & 1999 & 2000 & 2001 & 2002 & 2003 & 2004 & 2005 & 2006 & 2007 & 2008 \\
\hline Furto (outros) & 2608,92 & 3232,02 & 3506,4 & 3379,67 & 3552,27 & 3688,56 & 2317,8 & 2676,31 & 2903,47 & 941,27 \\
\hline Dano & 283,71 & 549,1 & 707,9 & 760,75 & 640,8 & 527,29 & 473,84 & 457,69 & 424,29 & 121,08 \\
\hline $\begin{array}{l}\text { Acid. trânsito } \\
\text { com dano }\end{array}$ & 379,44 & 335,45 & 415,48 & 420,84 & 333,07 & 319,1 & 332,04 & 405,17 & 525,29 & 212,47 \\
\hline Lesão acid. & & & & & & & & & & \\
\hline $\begin{array}{l}\text { trânsito homem } \\
\text { Lesão dolosa }\end{array}$ & 0 & 93,22 & 254,71 & 270,63 & 885,22 & 817,89 & 77,99 & 65,22 & 134,28 & 72,76 \\
\hline $\begin{array}{l}\text { contra homem } \\
\text { Lesão dolosa }\end{array}$ & 90,18 & 202,09 & 275,88 & 322,43 & 296,34 & 307,33 & 198,52 & 245,87 & 264,62 & 107,11 \\
\hline contra mulher & 86,02 & 207,53 & 263,97 & 263,51 & 272,91 & 331,49 & 114,03 & 307,63 & 230,77 & 65,78 \\
\hline Roubo & 90,87 & 94,58 & 171,35 & 168,98 & 177,3 & 161,1 & 117,57 & 150,64 & 172,09 & 59,96 \\
\hline Estelionato & 142,2 & 105,47 & 181,27 & 128,19 & 195,66 & 174,11 & 116,39 & 131,02 & 102,69 & 40,17 \\
\hline $\begin{array}{l}\text { Vias de fato } \\
\text { Lesão acid. }\end{array}$ & 35,38 & 27,9 & 68,14 & 93,88 & 112,08 & 128,88 & 150,66 & 113,12 & 139,93 & 12,81 \\
\hline trânsito mulher & 0 & 6,12 & 40,36 & 23,96 & 150,7 & 154,9 & 41,36 & 65,22 & 71,09 & 27,94 \\
\hline
\end{tabular}

Fonte: Banco de dados da polícia civil

Em todas as ocorrências tipificadas, há oscilações ao longo do período. Quanto aos furtos, o maior número de ocorrências foi no ano 2004 (3.688,56 registros por 100 mil habitantes). Em relação aos danos, o ano com maior número de ocorrências é 2002 (taxa de 760,75). Ainda relacionado aos danos, tem-se o acidente de trânsito com dano, cujas maiores taxas foram registradas em $2007(525,29)$ e $2002(420,84)$.

Também foi analisado o envolvimento do sexo masculino e feminino em algumas ocorrências registradas pela polícia civil do Município de Chapecó. Quanto à lesão por acidente de trânsito, o sexo masculino se destaca em todos os anos, sendo superior em até quatro vezes sobre o sexo feminino; $82 \%$ das ocorrências de lesão corporal em acidente de trânsito envolvem o sexo masculino, e apenas $12 \%$ o sexo feminino. Já as lesões corporais dolosas apresentam taxas próximas, mas ainda predominando o sexo masculino, com 47\%; o sexo feminino corresponde a $44 \%$ das ocorrências, e $9 \%$ abrange menores de idade.

Na polícia militar, as práticas violentas mais registradas, como se pode verificar na Tabela 4, são os acidentes de veículos com danos materiais, em primeiro lugar, seguido de acidentes de veículos com lesões corporais, vias de fato ou agressão, furto a residência, furto consumado (quando o objeto do crime sai completamente da esfera de domínio da vítima, ocorrendo a inversão da posse do objeto), arrombamento ou furto em veículo, lesões corporais, furto tentado (o fato não é executado por completo), furto a estabelecimento comercial e furto de veículo. Dentre os registros de acidentes de veículos com danos materiais, o ano 2008 se destaca, com 2.081,04 ocorrências, seguido de 2007 (1.881,67). 
Tabela 4. Taxa (por 100 mil habitantes) dos principais registros da polícia militar - Chapecó/SC

\begin{tabular}{lllllllllll}
\hline Delitos & 1999 & 2000 & 2001 & 2002 & 2003 & 2004 & 2005 & 2006 & 2007 & 2008 \\
\hline Acid. veícul. & & & & & & & & & & \\
danos materiais & 374,59 & 700,84 & 1246,43 & 1339,57 & 1494,36 & 1767,76 & 1715,16 & 1641,45 & 1881,67 & 2081,04 \\
Acid. veícul. lesões corp. & 129,02 & 279,65 & 494,2 & 606,01 & 721,22 & 746,63 & 700,13 & 677,01 & 605,97 & 653,13 \\
Vias de fato ou agressão & 396,78 & 46,27 & 373,8 & 661,69 & 611,68 & 517,38 & 742,08 & 720,3 & 602,59 & 795,16 \\
Furto a residência & 167,87 & 48,99 & 403,57 & 635,14 & 769,98 & 659,27 & 489,79 & 780,33 & 560,27 & 593,75 \\
Furto consumado & 122,09 & 34,7 & 270,59 & 411,78 & 508,46 & 534,11 & 528,2 & 576,01 & 563,09 & 464,52 \\
Arrombamento/ & & & & & & & & & & \\
furto veículo & 70,76 & 48,99 & 366,52 & 653,27 & 666,13 & 641,92 & 470,89 & 422,48 & 344,17 & 316,09 \\
Lesões corporais & 86,71 & 23,13 & 236,85 & 387,82 & 466,67 & 485,78 & 427,76 & 421,33 & 451,38 & 367,89 \\
Furto tentado & 124,17 & 31,3 & 211,05 & 387,82 & 395,12 & 431,87 & 343,27 & 422,48 & 331,76 & 319 \\
Furto estabel. comercial & 73,53 & 19,05 & 124,38 & 224,66 & 265,31 & 269,53 & 249,33 & 268,38 & 239,23 & 294,55 \\
Furto de veículo & 27,05 & 8,17 & 52,27 & 127,55 & 157,67 & 254,66 & 231,01 & 291,47 & 353,77 & 317,83 \\
\hline
\end{tabular}

Fonte: Banco de dados da polícia militar

Os acidentes de veículos com lesões corporais apresentam maiores taxas nos anos 2004 e 2005, com 746,63 e 700,13 respectivamente. Tanto os acidentes de veículos com danos materiais quanto com lesões corporais apresentam um crescimento significativo das ocorrências no período pesquisado, principalmente os acidentes com danos materiais, que demonstram um crescimento contínuo de 1999 a 2008.

\section{Discussão}

\section{Violências e direitos humanos: referências e desafios}

As informações descritas, pela abrangência de diferentes práticas, possibilitam compreender a necessidade do envolvimento de vários setores na discussão sobre violências: saúde, segurança pública, trânsito, trabalho e assistência social, que implicam ações municipais, estaduais e da federação.

Hoje uma importante referência para a discussão da segurança é a $1^{\text {a }}$ Conferência Nacional de Segurança Pública (CONSEG), realizada em 2009, a qual definiu, como princípio número três, que a segurança pública deve

Ser pautada pela defesa da dignidade da pessoa humana, com valorização e respeito à vida e à cidadania, assegurando atendimento humanizado a todas as pessoas, com respeito às diversas identidades religiosas, culturais, étnico-raciais, geracionais, de gênero, de orientação sexual e as das pessoas com deficiência. Deve ainda combater a criminalização da pobreza, da juventude, dos movimentos sociais e seus defensores, valorizando e fortalecendo a cultura de paz (p. 80)

A 1a CONSEG também elegeu como uma das suas diretrizes o reconhecimento jurídico-legal da importância do Município como cogestor da área, fortalecendo sua atuação na prevenção social do crime e das violências. Essa diretriz abre espaço e consolida a participação da comunidade na definição de prioridades e ações de segurança com base em suas necessidades locais. 
Historicamente, segundo Miraglia (2008), a segurança foi desempenhada sobretudo pelos governos estaduais, mesmo constando no texto da Constituição Federal Brasileira que é tarefa compartilhada. O Município surge como um importante ator e passa a assumir um papel complementar à atuação das outras esferas do governo, com políticas de atribuições compartilhadas. Essa mudança foi decorrente da percepção de suas potencialidades de ação:

A prefeitura é o braço do poder público mais próximo à população, é onde se dá a prestação cotidiana de serviços, é também quem conhece os problemas e conflitos da comunidade mais de perto e pode, portanto, solucioná-los com maior agilidade quando ainda têm proporções reduzidas. Ao mesmo tempo, a proximidade com a comunidade agrega outro capital ao poder municipal: a capacidade de mobilização e a articulação da população em geral (Miraglia, 2008, p. 89)

Portanto, as ações municipais de segurança precisam abranger, além da prefeitura, associações comunitárias, fóruns de discussão e de mobilização de pessoas, grupos e instituições interessadas na produção de conhecimento sobre realidades onde se produzem violências, e na elaboração, operacionalização e avaliação de políticas públicas para o seu enfrentamento. Como afirma Soares (2006, p. 96), é "o conhecimento de cada bairro, região da cidade, praça ou rua" que possibilita a consistência de cada ação, de cada projeto, de cada programa e a qualidade de uma política.

Desse modo, é importante considerar a necessidade de ruptura do modelo tradicional de segurança pública, ainda predominante no Brasil, focado no controle repressivo e punitivo do crime. Como afirma Wacquant (2003), vivemos em uma sociedade penal, com a presença de um Estado penal muito mais preocupado em reprimir o crime do que em manter políticas públicas voltadas para a manutenção do bem-estar social.

As diretrizes das conferências referidas contribuem para a produção de rupturas à lógica penal, ao afirmar a segurança pública como direito fundamental, reconhecer a necessidade de reformas estruturais no modelo organizacional de suas instituições nos três níveis de governo e ao garantir o acesso aos sistemas de Justiça e de segurança pública a todos. Para a construção da lógica da segurança social, além das diretrizes, torna-se fundamental a mobilização de pessoas, grupos e organizações para problematizar situações de violências naturalizadas, questionar e propor políticas sociais e reivindicar direitos conquistados. O desafio é o encadeamento de ações conjuntas da sociedade civil com o Estado.

Outro ponto importante é a compreensão da necessidade do envolvimento de diferentes áreas na gestão da segurança, que deixa de ser competência exclusiva da polícia para converter-se em tema transversal do conjunto de políticas públicas (Kahn \& Zanetic, 2009), buscando o enfrentamento das violências a partir do conjunto dessas políticas públicas e ações sociais. Segundo Miraglia (2008, p. 90), "a interface dos problemas se reproduz na interface das soluções", ou seja, as violências são produzidas por uma multiplicidade de fatores, o que demanda uma multiplicidade de estratégias de enfrentamento.

Nessa mesma direção caminham as resoluções da $11^{\text {a }}$ Conferência Nacional de Direitos Humanos, realizada em 2008, que define quanto à garantia de direitos relacionados à violência e à segurança:

Apoiar a criação de mecanismos que atuem na prevenção à violência nas comunidades e regiões mais precárias do País, por meio de: a) efetivação dos serviços públicos, como importantes estruturas universais, b) fortalecimento de programas e projetos de saúde, educação, segurança, cultura e habitação, entre outros serviços essenciais, c) impedimento da crescente privatização e precariedade dos serviços fundamentais e recursos humanos, nas políticas públicas de segurança penitenciária e d) efetivação de políticas públicas de enfrentamento à violência sexual no sentido de garantir os direitos do segmento infanto-juvenil (p. 43) 
É indispensável também considerar que as violências afetam fortemente a saúde, provocando mortes, lesões, traumas físicos, agravos mentais e emocionais, diminuindo "a qualidade de vida das pessoas e coletividades" e exigindo "uma readequação organizacional dos serviços de saúde" (Minayo, 2006, p. 45). Além disso, as violências evidenciam a necessidade de uma atuação interdisciplinar, multiprofissional, intersetorial e engajada, visando às necessidades dos cidadãos.

\section{Pensando possibilidades de ações a partir da realidade pesquisada}

Para se avaliar as políticas de prevenção dos acidentes de trânsito, que, como vimos, se destacaram em primeiro lugar tanto na mortalidade por causas externas quanto nos boletins de ocorrência registrados pela polícia militar, torna-se importante conhecer e considerar os atores que compõem a rede tecida por esses eventos. Compreende-se rede como uma estrutura composta de elementos em interação, que constituem atores (humanos e não humanos) que a tecem, compondo conexões e agenciamentos provisórios e produzindo efeitos no mundo (Latour, 2006).

Segundo Zanchet (2009), a gestão municipal do trânsito acompanha a organização nacional e os princípios descritos no Código de Trânsito Brasileiro; em Chapecó, envolve o gerenciamento e a organização da Secretaria de Defesa do Cidadão, também responsável por sua fiscalização junto com a Polícia Militar, que atende os casos de acidentes, fazendo os boletins de ocorrência. Os bombeiros e o Serviço de Atendimento Móvel de Urgência (SAMU) atendem os casos de acidentes com vítimas, e a polícia civil faz a apuração das infrações penais. A partir da pesquisa realizada, a autora identifica algumas ações de condutores que contribuem para a ocorrência de acidentes: o desrespeito às regras de trânsito, o excesso de velocidade e a condução do veículo por motorista alcoolizado. No entanto, o condutor é apenas um dos atores, sendo importante considerar também outros atores que fazem conexões e produzem efeitos no trânsito, como o espaço geográfico, a forma das vias, a sinalização, o pedestre, as normas e o número de veículos (em 2009, havia 1,66 habitantes para cada veículo registrado em Chapecó).

Com relação aos homicídios, apesar de as informações seguirem a tendência nacional, ainda se considera importante a sua descrição em nível municipal para pensarmos em políticas públicas locais que, por exemplo, estimulem o desarmamento, já que a arma de fogo é o principal meio utilizado, e que sejam direcionadas às faixas etárias mais atingidas. Além disso, é necessário realizar outras pesquisas (qualitativas e quantitativas) que possam contribuir para se conhecer, por exemplo, as redes que compõem as práticas dos homicídios, os principais atores envolvidos e os interesses que configuram as ações em contextos específicos, pois, como destacam Soares, Souza e Moura (2009), os homicídios dolosos apresentam diversas etiologias, acontecem em diferentes locais e apresentam diferentes dinâmicas; necessitam, assim, de diagnóstico contextualizado. É necessário conhecer o contexto de fatores influentes que possam servir de base para estabelecer determinados objetivos.

Para a elaboração de políticas públicas de enfrentamento e de prevenção de homicídios, é importante ainda, segundo Soares et al. (2009), abordar a perspectiva de gênero, pois esta envolve especificidades como a tendência de a vitimização masculina ocorrer fora de casa e de seus autores serem estranhos, conhecidos ou amigos, e os homicídios de mulheres ocorrerem mais dentro de casa, cometidos por seus ex ou atuais companheiros, o que novamente remete a discussões que demandam a realização de pesquisas que tratem dessas problemáticas em contextos específicos.

É importante, ainda, considerar os múltiplos fatores que se conectam na configuração de crimes. Ferreira, Lima e Bessa (2009, p. 13) analisam que "a incidência da violência e do crime sofre influência da conjuntura social e 
demográfica, da presença de fatores de risco, da execução de políticas sociais e urbanas e de estratégias de prevenção, entre outras ações".

Os autores destacam alguns fatores que contribuíram com a queda dos indicadores de violência e do crime em São Paulo: a) gestão das políticas de segurança pública pela Secretaria de Segurança Pública, em especial as reformas gerenciais focalizadas e o planejamento estratégico dos últimos dez anos, b) o aprimoramento técnico policial, a gestão de Justiça e as instituições de segurança pública pelo Governo Federal e o do Estado de São Paulo, c) o aumento dos recursos públicos destinados à área de segurança pública em São Paulo, d) o Estatuto do Desarmamento, que possibilitou a retirada de armas de circulação, e) a entrada das prefeituras municipais na agenda da segurança pública, por meio de principalmente cinco políticas de natureza municipal: criação de guardas municipais, institucionalização de conselhos, secretarias e planos municipais de segurança, acesso aos recursos do Fundo Nacional de Segurança Pública e a criação, em algumas cidades, da lei de restrição de funcionamento de bares e venda de bebidas alcoólicas, f) movimentos da sociedade civil, organizações sociais e comunidade, integrando a população vulnerável como atores das políticas de combate à violência, g) diminuição de disputas territoriais por facções criminosas, h) redução do número de jovens, que era o segmento mais exposto aos riscos de violência, devido à queda de fecundidade que ocorreu a partir da década de 80 , o que diminuiu as taxas de homicídios, i) a elevação da escolaridade da população em geral, em especial dos mais jovens e j) conjuntura econômica favorável à entrada de amplos segmentos sociais no mercado de trabalho (Ferreira et al., 2009).

Os fatores apontados permitem que se torne visível a multidimensionalidade presente na configuração dos homicídios, a qual deve ser considerada nas ações políticas e sociais para o seu enfrentamento.

O suicídio também é uma prática complexa e multifatorial, sendo necessário o conhecimento dos fatores de risco para ações preventivas. Segundo Abreu, Lima, Kohlrausch e Soares (2010), os fatores de riscos mais importantes são: sexo, idade, transtornos mentais, antecedentes familiares, relações familiares, abuso de substâncias, problemas físicos e/ ou dor crônica e situação socioeconômica desfavorável. É importante também levar em conta, no caso do Município estudado, o perfil étnico (descendentes de imigrantes europeus) e a atividade econômica (agroindustrial), pois, segundo Schmitt, Lang, Quevedo e Colombo (2008), esses fatores estão presentes em áreas com altas taxas de suicídio no Rio Grande do Sul e em Santa Catarina, e devem ser mais bem investigados.

A conjugação entre os fatores biológicos, culturais e psicossociais mostra a importância da atenção integral aos indivíduos para a prevenção do suicídio. Uma das possibilidades de intervenção é na atenção primária à saúde, a partir da promoção da saúde mental e por meio do acesso a necessidades básicas, como alimentação, moradia, educação, cultura e lazer. Para Abreu et al. (2010), as ações devem incluir pessoas em situações de agravos de saúde e programas em escolas e comunidades para a redução de violências e do consumo de álcool e drogas; também devem ser direcionadas para a formação dos profissionais de saúde a fim de que riscos sejam identificados nos usuários e estratégias de prevenção sejam desenvolvidas. A composição da equipe interdisciplinar é fundamental para que aconteça a integralidade do atendimento, a partir de vários saberes.

Há muitas possibilidades de se analisar os furtos (atos de apropriação de bens alheios sem que a vítima o perceba na hora da efetivação deste) e roubos (atos de apropriação de bens alheios em que a vítima percebe no momento do ato), que configuram crimes contra o patrimônio. Beato, Peixoto e Andrade (2004) examinam as circunstâncias em que os crimes ocorrem, a partir de informações provenientes de pesquisa de vitimização realizada em Belo Horizonte, e constatam que são estes os fatores que mais influenciam a vitimização: exposição (tempo em que os indivíduos permanecem em locais 
públicos), proximidade da vítima ao agressor, capacidade de proteção, atrativos da vítima e natureza dos delitos. Identificam que as taxas de vitimização são distintas nos diferentes grupos e segmentos sociais, incidindo mais em indivíduos com nível superior, de renda mais elevada, que andam de transporte público, em horário de maior fluxo e à noite, que residem em locais onde existem muitos prédios abandonados e onde se escuta barulho de tiros. Para os autores, "a estrutura urbana municipal seria um dos elementos da estrutura de oportunidades que levam à ocorrência de crimes" (Beato et al., 2004, p. 86), devendo ser considerada, portanto, na proposição de políticas públicas.

Bonamigo (2008a), a partir do estudo de um furto cometido por uma criança e dois adolescentes, em Chapecó, chama a atenção para a necessidade de se considerar a rede extensa que sustenta um furto, a qual inclui, no caso estudado, além da criança e dos adolescentes, outros atores, como o receptador da mercadoria furtada, a droga, o traficante e o policial, dentre outros. Portanto, a rede e os atores a ela vinculados devem ser considerados nas políticas públicas de segurança.

Em Chapecó, identificaram-se ainda, conforme apresentado, taxas de agressão registradas pelas polícias civil e militar, com a predominância nos registros da polícia civil do sexo masculino; no entanto, não foi possível investigar as circunstâncias em que essas agressões ocorreram. Alba Zaluar afirma que a agressão física, quando comparada a outros crimes como furtos e roubos, tem características peculiares: "obedece a motivações e circunstâncias específicas, muito mais relacionadas com as interações e emoções entre as pessoas envolvidas do que com a oportunidade, muito mais relacionada com o poder e reconhecimento simbólico para o agressor do que com ganhos materiais obtidos" (Zaluar, 2009, p. 10). A partir de informações provenientes de inquérito domiciliar de vitimização realizado no Rio de Janeiro, a autora identificou diferentes padrões entre homens e mulheres no que diz respeito à agressão física: 73,7\% das agressões masculinas ocorreram em espaços públicos, e $57,8 \%$ das agressões femininas ocorreram em ambientes domésticos e privados. Como se pode perceber, essas diferenças entre homens e mulheres estão presentes nos padrões tanto de agressão física quanto de homicídio, citado anteriormente, e devem ser consideradas na discussão das políticas públicas.

Um dos resultados da presente pesquisa é a identificação dos homens como principais vítimas das práticas violentas, destacandose principalmente a faixa etária entre 20 e 49 anos. Vários estudos discutem a relação entre masculinidade e violência no Brasil (Cecchetto, 2004; Souza, 2005; Gomes, 2003; Zaluar, 2009), visto que os homens são os que mais se envolvem em práticas violentas, tanto como vítimas quanto como autores.

Zaluar (2009, p. 22), a partir de Norbert Elias, discute vulnerabilidades e retrocessos no processo histórico de desenvolvimento do habitus civilizado, destacando a presença do ethos guerreiro: "formação subjetiva em que não se interiorizam os controles da emoção que tornam o sujeito capaz de evitar uma resposta belicosa a desafios e disputas". A inibição de características consideradas femininas (empatia, cuidado, proteção) e o reforço de características compreendidas como viris (dominação, uso de bebidas alcoólicas e perigo, dentre outras) facilitaria respostas agressivas a qualquer conflito e dificultaria práticas de civilidade e de igualdade entre pessoas e gêneros.

Cecchetto (2004) aborda a conexão entre violência e masculinidade a partir de pesquisa com grupos de frequentadores de bailes funk e de praticantes de jiu-jítsu, compreendendo a masculinidade como uma construção histórica e social. A autora conclui, a partir das singularidades encontradas, que é impossível fazer qualquer generalização com base no sexo, na idade e na classe social com relação a práticas violentas. 
Souza ressalta que as imensas desigualdades socioeconômicas, estruturais da sociedade e estruturantes das identidades de gênero, "constituem o pano de fundo que serve de cenário para a maior vulnerabilidade do gênero masculino vir a se envolver com a violência, ora como autor, ora como vítima" (2005, p. 62). Nesse sentido, é imprescindível que as políticas públicas, mais do que focar o que significa ser um homem-não-violento, abordem "questões políticas do que significa criar um mundo mais justo e menos violento" (Souza, 2005, p. 67). Isso implica, por exemplo, considerar que muitos se arriscam em situações violentas pela precariedade de suas condições de vida, por não vislumbrarem outras perspectivas, pelo vínculo com o tráfico de drogas, pela valorização da competitividade e do individualismo e pela banalização do uso de armas.

É importante, como sugere Zaluar (2009, p. 23), que as políticas públicas de prevenção de violências promovam "a construção de redes de solidariedade na vizinhança e na família, aumentando o nível de confiança mútua e promovendo a ação coletiva dos moradores e dos familiares". Para tal, muito pode contribuir a Psicologia, em especial a social comunitária, a partir de intervenções interdisciplinares e intersetoriais.

\section{Conclusão}

Este artigo partiu da pesquisa de levantamento de índices oficiais de práticas violentas para discutir diretrizes que visam à garantia dos direitos humanos e das políticas públicas para o enfrentamento de violências contemporâneas. Compreende-se que, apesar dos limites presentes nos registros que constituem as fontes oficiais, os indicadores levantados permitem identificar algumas tendências que contribuem para se pensar sobre políticas e ações sociais, tendo com referência a realidade municipal.

As violências que mais se destacaram nos registros oficiais relativos ao Município de Chapecó foram: acidentes de transporte, homicídios, suicídios, furtos, agressões (lesões corporais) e roubos. Conforme discutido, essa diversidade de práticas, que acontecem em vários espaços, a partir de situações e motivações diferenciadas, implica múltiplos fatores de determinação e mostra a complexidade que envolve os diagnósticos e as intervenções, exigindo abordagens interdisciplinares e intersetoriais. Desse modo, é necessário compreender as violências como um tema transversal do conjunto de políticas públicas, e os Municípios, como co-gestores da área de segurança e na prevenção de violências.

Torna-se importante complementar a investigação das práticas que se destacaram com estudos qualitativos e quantitativos, pois envolvem diferentes redes em suas composições, com uma infinidade de atores a elas vinculados. É necessário, então, conhecer as suas particularidades, pois como afirma Bonamigo (2008b), as violências devem ser tomadas como resultados de processos que envolvem mediadores em sua fabricação, e, além das práticas violentas propriamente ditas, devem ser considerados os modos como são registradas, os significados a elas atribuídos e as estratégias de gestão e controle.

A Psicologia pode contribuir a partir da realização de estudos que identifiquem tanto os dispositivos de produção de violências quanto as alternativas para o seu enfrentamento; pode ainda realizar intervenções que contribuam para a mobilização de pessoas e comunidades na criação de estratégias coletivas e participativas para a definição e o acompanhamento das ações de segurança. Nos dois casos, é importante a integração com outras áreas de conhecimento, a partir de ações inter e transdisciplinares e intersetoriais.

Um desafio fundamental para o enfrentamento das violências que se coloca para toda a sociedade é a produção da cidadania, da solidariedade, do respeito e da valorização dos direitos humanos. 


\section{Irme Salete Bonamigo}

Doutora em Psicologia Social pela Universidade do Estado do Rio de Janeiro (UERJ), docente do Curso de Psicologia e Mestrado em Políticas Sociais e Dinâmicas Regionais, Universidade Comunitária da Região de Chapecó (Unochapecó), Chapecó, SC - Brasil.

E-mail: bonamigo@unochapeco.edu.br

\section{Karin Bruxel}

Mestre em Psicologia pela Universidade Federal de Santa Catarina (UFSC), docente do Curso de Psicologia, Universidade Comunitária da Região de Chapecó (Unochapecó), Chapecó, SC - Brasil.

E-mail: karinbru@unochapeco.edu.br

Eliandra Solivo

Graduanda em Psicologia, Universidade Comunitária da Região de Chapecó (Unochapecó), Chapecó, SC - Brasil. E-mail: eliandraso@unochapeco.edu.br

\section{Francieli Fernanda Tremea}

Psicóloga, Universidade Comunitária da Região de Chapecó (Unochapecó), Chapecó, SC - Brasil.

E-mail: franci728@unochapeco.edu.br

\section{Cristiane Dameda}

Graduanda em Psicologia, Universidade Comunitária da Região de Chapecó (Unochapecó), Chapecó, SC - Brasil. E-mail:crisdameda@gmail.com

\section{Cristiane Martini}

Graduanda em Psicologia, Universidade Comunitária da Região de Chapecó, (Unochapecó), Chapecó, SC - Brasil. E-mail: cris.mart@unochapeco.edu.br

\section{Endereço para envio de correspondência:}

Avenida Senador Atílio Fontana, 591-E, Bairro Efapi, Chapecó - SC. Cep: 89809-000 - Caixa Postal: 1141

Recebido 28/7/2010, 1a Reformulação 14/7/2011, Aprovado 12/8/2011.

Abreu, K. P., Lima, M. A. D. S., Kohlrausch, E., \& Soares, J. F. (2010). Comportamento suicida: fatores de risco e intervenções preventivas. Revista Eletrônica de Enfermagem, 12(1), 195-200

Beato F., C., Peixoto, B., \& Andrade, M. (2004). Crime, oportunidade e vitimização. Revista Brasileira de Ciências Sociais, 19, 55.

Bonamigo, I. S. (2007). Violências na contemporaniedade: etnografia de redes sociotécnicas na cidade de Chapecó (SC). Tese de doutorado, Universidade do Estado do Rio de Janeiro (UERJ), Rio de Janeiro.

Bonamigo, I. S. (2008a, set./dez). Tecendo relato, versões e cenas: etnografia de um evento violento. Psicologia \& Sociedade, 20(3), 350-359.

Bonamigo, I. S. (2008b). Violências e contemporaneidade. Revista Katálysis, 11(2) 157-300.

Cechetto, F. R. (2004). Violência e estilos de masculinidade. Rio de Janeiro: FGV.

Ferreira, S. P, Lima, R. S., \& Bessa, V. (2009). Criminalidade violenta e Homicídios em São Paulo: fatores explicativos e movimentos recentes. (Coleção Segurança com cidadania. Homicídios: políticas de controle e prevenção no Brasil, Ano 1, n. 3, 11-20)

Gomes, R. (2003). Sexualidade masculina e saúde do homem: proposta para uma discussão. Ciência \& Saúde Coletiva, 8(3), 825-829.

Khan, T., \& Zanetic, A. (2009). O papel dos municípios na segurança pública. Brasília: Secretaria Nacional de Segurança Pública do Ministério da Justiça (Coleção Segurança com cidadania, Ano I, n. 1).

Latour, B. (2006). Changer de société. Refaire de la sociologie. Paris: La Découverte.

Michaud, Y. (1989). A violência. São Paulo: Editora Ática.
Minayo, M. C. S. (2006). Violência e saúde. Rio de Janeiro: Editora Fiocruz.

Miraglia, P. (2008). Os municípios e a segurança pública. In S. Lima, \& L. Paula Segurança pública e violência: o Estado está cumprindo o seu papel? (pp.88-99). São Paulo: Contexto,

Relatório final da $7^{\text {a }}$ Conferência Nacional de Segurança Pública. (2009). Brasília: Ministério da Justiça.

Resoluções aprovadas na $11^{\text {a }}$ Conferência Nacional de Direitos Humanos. (2008). Brasília: Secretaria Especial de Direitos Humanos.

Schmitt, R., Lang, M., Quevedo, J. \& Colombo, T. (2008). Perfil epidemiológico do suicídio no extremo oeste do estado de Santa Catarina, Brasil. Ver. Psiquiatr. RS, 30(2), 115-123.

Soares, L. E. (2006). Segurança pública: presente e futuro. Estudos Avançados, 20(56), 91-106.

Soares, G., Souza, C., \& Moura, M. (2009). Gênero e vitimização por homicídio. (Coleção Segurança com cidadania. Homicídios: políticas de controle e prevenção no Brasil, Ano 1, n. 3)

Souza, E., R. (2005). Masculinidade e violência no Brasil: contribuições para reflexão no campo da saúde. Ciência \& Saúde Coletiva, 10(1), 59-70.

Wacquant, L. (2003). Punir os pobres: a nova gestão da miséria nos Estados Unidos (a onda punitiva). Rio de Janeiro: Revan.

Waiselfisz, J. (2006). Mapa da violência 2006: os jovens do Brasil. Brasília: Organização dos Estados Íbero-americanos para a Educação, a Ciência e a Cultura (OEI).

Zaluar, A. (2009). Agressão física e gênero na cidade do Rio de Janeiro. Rev bras. Ci. Soc. 24(71), 9-24.

Zanchet, A. M. (2009). Trânsito e violências em Chapecó (SC): um olhar a partir da teoria ator-rede. Trabalho de conclusão de curso, Universidade Comunitária da Região de Chapecó (Unochapecó), Chapecó, SC. 